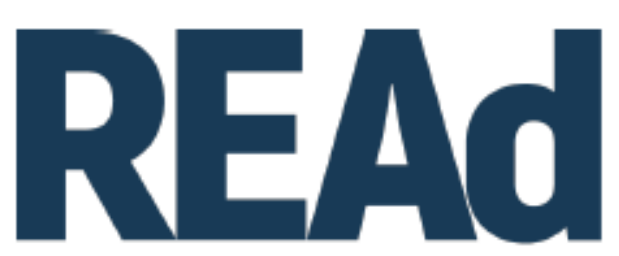

Revista Eletrônica de Administração

\title{
VIDA UNIVERSITÁRIA NOS CURSOS DE ADMINISTRAÇÃO: JOGOS VORAZES OU OS MELHORES ANOS DE NOSSAS VIDAS? ${ }^{1}$
}

\author{
Hélio Arthur Reis Irigaray ${ }^{2}$ \\ Alessandro Vendramini Langerhorst ${ }^{3}$ \\ Daniel Adorno ${ }^{4}$
}

http://dx.doi.org/10.1590/1413-2311.318.103971

\begin{abstract}
RESUMO
O objetivo deste estudo é apreender como as diferentes identidades dos alunos dos cursos de graduação em Administração de Empresas são reconhecidas nas interações sociais. Neste sentido, conduzimos uma pesquisa empírica com 73 alunos de diferentes gêneros, cores de pele, classes sociais, religiões e orientações sexuais, de quatro instituições de ensino superior. Esta pesquisa é de cunho etnográfico e a coleta de dados se deu por meio de notas de campo e entrevistas, as quais foram gravadas, transcritas e submetidas à Análise Crítica do Discurso. $\mathrm{O}$ campo revelou que os alunos do sexo masculino, brancos, heterossexuais e de alto poder aquisitivo, tornam perigosamente irracionais, na medida em que se engajam em atos de violência moral e física contra seus pares pertencentes a grupos minoritários. Esta violência revelou-se institucionalizada no ambiente acadêmico por meio de micropráticas sociais, e ficou claro que o objetivo das mesmas é a preservação do capital socioeconômico-político, que é assegurado pela hegemonia masculina, a qual se reifica por meio da desqualificação de interesses e direitos legítimos dos alunos que não pertencem ao grupo dominante. As principais implicações deste estudo são a necessidade de reformularmos os conteúdos dos cursos de graduação, bem como a criação e institucionalização de políticas e práticas que coíbam os comentários e comportamentos discriminatórios no ambiente universitário.
\end{abstract}

\footnotetext{
${ }^{1}$ Recebido em 6/6/2020, aceito em 10/5/2021.

${ }^{2}$ FGV- Escola Brasileira de Administração Pública e de Empresas - Programa de Pós-graduação em Administração de Empresas; Rio de Janeiro (RJ), Brasil; http://orcid.org/0000-0001-9580-7859; helio.irigaray@ fgv.br.

3 Universidade Federal da Bahia - Bacharelado em Estudos de Gênero e Diversidade; Salvador (BA), Brasil; http://orcid.org/0000-0002-6280-4827; alessandrolangerhorst@ gmail.com.

${ }^{4}$ FGV- Escola Brasileira de Administração Pública e de Empresas - Bacharelado em Administração; Rio de Janeiro (RJ), Brasil; http://orcid.org/0000-0001-9822-0017; daniel.adorno@ gmail.com.
} 
Palavras-chave: Heterocentrismo. Hegemonia masculina. Gênero. Discriminação. Classe Social.

\section{COLLEGE LIFE IN THE UNDERGRADUATE COURSE OF BUSINESS ADMINISTRATION: HUNGER GAMES OR THE BEST YEARS OF OUR LIVES?}

The aim of this work is to reveal how the different identities of students of undergraduate course in Business Administration are recognized in their social interaction; thus, we have conducted an empirical research with 73 students of different genders, skin color, social classes, religions and sexual orientations, from four higher education institutions. This research is of an ethnographic nature and the data collection took place through field notes and interviews, which were recorded, transcribed and submitted to Critical Discourse Analysis. The field revealed that male students, white, heterosexual and with high purchasing power, became dangerously irrational, as they engaged in acts of moral and physical violence against their peers belonging to minority groups. This violence proved to be institutionalized in the academic environment through social micropractices, and it was clear that their objective is the preservation of socioeconomic-political capital, which is ensured by male hegemony, which is reified through the disqualification of interests and legitimate rights of students who do not belong to the dominant group. The main implications of this study are the need to reformulate the content of undergraduate courses, as well as the creation and institutionalization of policies and practices that curb discriminatory comments and behavior in the university environment.

Keywords: Heterocentrism. Male Hegemony. Genre. Discrimination. Social class.

\section{VIDA UNIVERSITARIA EN LOS CURSOS DE ADMINISTRACIÓN: ¿JUEGOS DEL HAMBRE O LOS MEJORES AÑOS DE NUESTRAS VIDAS?}

El objetivo de este estudio es analizar cómo las interacciones sociales dentro del entorno académico resultan en actitudes discriminatorias. Se entrevistó a 73 estudiantes, con edades entre 19 y 27 años, de diferentes géneros, color de piel, clases sociales, religiones y orientaciones sexuales, de cuatro cursos de pregrado en Administración. Las entrevistas fueron transcritas y sometidas a análisis crítica del discurso. El campo reveló que los estudiantes varones, blancos, heterosexuales y con alto poder adquisitivo, se volvieron peligrosamente irracionales, ya que participaron en actos de violencia moral y física contra sus compañeros pertenecientes a grupos minoritarios. Esta violencia demostró ser institucionalizada en el entorno académico a través de microprácticas sociales, y quedó claro que su objetivo es la preservación del capital socioeconómico-político, que está garantizado por la hegemonía masculina, que se reifica mediante la descalificación de intereses y Derechos legítimos de los estudiantes que no pertenecen al grupo dominante. Las principales implicaciones de este estudio son la necesidad de reformular el contenido de las carreras de grado, así como la creación e institucionalización de políticas y prácticas que frenen los comentarios y comportamientos discriminatorios en el ámbito universitario.

Palabras clave: Heterocentrismo. Hegemonía masculina. Género. Discriminación. Clase social. 


\section{INTRODUÇÃO}

Não raramente, a vida universitária tem sido retratada em filmes, novelas e livros como uma sucessão de bons e divertidos momentos, permeados por amizades, pequenas rivalidades, encontros românticos e vida sexual agitada (OLFERT; BARR; CHARLIER; GREENE; SHOW; COLBY, 2019).

Todavia, ao longo dos anos, são comuns relatos de alunos e alunas sobre experiências de bullying (SWEARER; HYMEL, 2015), discriminação, assédio e violência no ambiente acadêmico, em função de gênero, cor da pele, classe social, orientação afetivo-sexual, religião, naturalidade, tipo de corpo e deficiência física (IRIGARAY; GALATOLLI: AMORIM, 2017). Mas, como essas diferentes identidades são reconhecidas nas interações sociais nas universidades? Assim ficou formulada nossa pergunta de investigação.

Para respondê-la, elaboramos esta pesquisa empírica, a qual se limitou aos cursos de graduação em Administração de Empresas, de diferentes instituições de ensino superior (IES), localizadas na região metropolitana do Rio de Janeiro.

Este trabalho foi idealizado sobre as premissas ontológicas da pós-modernidade, dado que acreditamos na existência de realidades e identidades múltiplas e simultâneas (BAUDRILLARD, 1968), sendo que estas últimas são construídas a partir da linguagem e relatos de experiências pessoais (BENHABIB, 2005); portanto, um indivíduo e seu mundo são elementos indissociáveis (BOJE, 2005) e a compreensão dos significados das ações sociais deve ser apreendida sob o olhar dos próprios sujeitos, e não da visão dos pesquisadores (HASSARD, 2003).

Metodologicamente, no sentido de apreender a percepção dos alunos de diferentes traços identitários, optamos pela etnografia, método originado da Antropologia que se coloca em um paradigma interpretacionista da realidade social. A etnografia leva os pesquisadores ao campo, onde buscam, pela interação com as pessoas, informações necessárias, assim a coleta de dados se consistiu de técnicas de observação sistemática e participante, bem como das histórias de vida e depoimentos (WODAK, 1997).

Por outro lado, neste estudo, como um dos pesquisadores é um aluno transexual, nossa pesquisa no campo teve também um caráter autoetnográfico (ALVESSON, 2003). Se, a esse 
pesquisador foi exigido certo estranhamento, certo distanciamento da realidade, na qual está inserido, para poder sobre ela melhor refletir; aos outros dois, foi exigida sensibilidade para captar os sentimentos de todos os entrevistados.

Os dados coletados foram submetidos à análise crítica do discurso (ACD), que parte do princípio de que o discurso tem poder constitutivo, pois cria formas de conhecimentos e crenças, relações sociais e identidades (FAIRCLOUGH, 2008). Ela pressupõe que a compreensão do modo como o discurso cria, mantém ou questiona relações de dominação e poder, bem como explica as estruturas do discurso a partir das propriedades da interação social e, especialmente, da estrutura social mais ampla (MEURER, 2005), desvelando, assim, como as estruturas do discurso produzem, reproduzem, legitimam ou desafiam as relações de poder e de dominação na sociedade. Dessa forma, a ACD tem uma função emancipatória explícita para o sujeito dominado, na medida em que busca proporcionar a ele recursos e ferramentas de análise adequadas para realizar uma leitura crítica de discursos próprios e alheios, posicionando-se contra situações de dominação das quais, nem sempre, se dá conta.

Entendemos que a relevância deste estudo da mesma jaz no reconhecimento da existência de diferentes grupos sociais dentro das nossas salas de aula, o que impacta no próprio processo de aprendizagem (CANDAU, 2011), na formação da identidade dos alunos (DIAS; SOUZA-NETO, 2019), na conscientização dos mesmos sobre a importância da diversidade no ambiente de trabalho (FELIX, 2020), bem como a violência nas instituições de ensino superior (IES) em si (GODINHO, 2018).

Assim como outras organizações, nas IES também predomina o paradigma da neutralidade, tecnicismo e meritocracia (SARAIVA; IRIGARAY, 2009), o qual se pauta pela premissa funcionalista da homogeneidade dos indivíduos. No seu cotidiano, elas lidam com o corpo discente como se suas diferenças pudessem ser ocultadas sem maiores problemas sob o manto da formalidade, dos rituais e dos processos acadêmicos, partindo do pressuposto de que seus alunos separam suas características e interesses pessoais dos acadêmicos e subjugam sua dimensão de indivíduo ao "bem comum" organizacional (IRIGARAY; GALATOLLI: AMORIM, 2017).

Entretanto, essa visão é limitada, dado que existem racionalidades concorrentes dentro de qualquer organização e que, portanto, os indivíduos não apresentam qualquer tipo de clivagem entre quem realmente são e seus papeis sociais (BERLINCK, 2014); ou seja, o reconhecimento do "outro", que é um dos elementos fundamentais na construção da identidade 
do indivíduo (SAINSAULIEU, 1983), e que ocorre dinamicamente, a partir de interações sociais, dentro de um limite espaço-temporal (GOFFMAN, 2011), fica comprometido.

Este trabalho está estruturado em cinco seções, além desta introdução. A próxima é composta pelo marco teórico; no qual resgatamos os constructos interação social e hegemonia masculina. Na terceira, relatamos nosso percurso metodológico. Posteriormente, na quarta, apresentamos os resultados do trabalho de campo, os quais são, finalmente, discutidos à luz do referencial teórico, na quinta e última seção.

\section{INTERAÇÃO SOCIAL E HEGEMONIA MASCULINA}

$\mathrm{Na}$ perspectiva do interacionismo simbólico, a conduta humana é linear dado que a socialização primária dos indivíduos é a base da construção de suas identidades e que as pessoas se comportam de acordo com suas crenças (LUZ, 1993). O momento básico da interiorização dos valores e crenças seria a infância pós-eudipiana (BERGER; LUCKMANN, 1989), todavia, ela se prolonga durante toda a vida do indivíduo, tendo em vista a sua participação em novos universos de interação.

O interacionismo simbólico concilia o pressuposto weberiano de liberdade e escolha humana, no sentido que não seria apenas a estrutura das instituições ou a situação econômica do sujeito que motivaria suas ações. Assim, as ideias, as crenças e os valores constituem os principais catalizadores das mudanças sociais, dado que os indivíduos disporiam de liberdade para agir e modificar a sua realidade (WEBER, 1982). No limite, a ação social seria qualquer ação que possua um sentido e uma finalidade determinados pelo sujeito; ou seja, a ação passa a existir a partir da intenção do autor em relação à resposta que deseja daqueles com os quais interage, consequentemente, as interações humanas passam a ter sentido graças aos seus atores e seus esforços comunicativos.

O mesmo se observa no modelo parsoniano, no qual o sistema de valores é anterior a todos os outros sistemas sociais: a interiorização de normas e decisões tomadas pelos autores sociais seriam reguladas pela preexistência de valores incorporados pelo indivíduo em sua socialização primária (PARSON, 1937). Sob esta lógica, concluímos que os valores preexistentes no sistema social oferecem aos indivíduos, não só seus objetivos, mas também legitimam os meios sociais para atingi-los, por meio de regras e normas. 
Apesar de discordar da hipervalorização da socialização primária, Sainsaulieu (1983) reconhece a importância das vivências e da socialização passada do indivíduo na construção de sua racionalidade e estruturação do processo decisório; mas estes também dependem das condições, influências, problemas e experiências atuais.

Nesta mesma linha de raciocínio, Boudon (1991) argumenta que o processo de interação social pauta-se por dois efeitos: o de posição; isto é, a decisão depende da posição que o ator social ocupa em um contexto de ação específico e que condiciona seu acesso às informações pertinentes e, também, pelo de disposição (a decisão depende das características mentais, cognitivas e afetivas do indivíduo que decide, características essas pré-formadas por sua socialização passada).

Neste sentido, a hegemonia masculina (CONNEL; MESSERSCHMIDT, 2013) é um dos principais elementos constitutivos das sociedades ocidentais, inclusive a brasileira (HOLANDA; ARAÚJO; SCHWARTZ, 2006), e tem servido de base para a discriminação de grupos minoritários (GARCIA, 2017).

Hegemonia é o eixo central da discussão marxista, especialmente de Gramsci, que explica como a classe dominante estabelece e mantém seu poder e domínio sobre o proletariado. Ela consiste na persuasão da maioria da população por meio da mídia, das organizações e da institucionalização dos conceitos de "normal", "natural” e "comum". Já a noção de masculinidade historicamente se construiu e se associou a valores como "coragem", "autonomia", "habilidade", "aventura" e "solidariedade grupal" (IRIGARAY; FREITAS, 2013).

Desta forma, o conceito de hegemonia masculina jaz na questão de como um grupo particular de homens - brancos, heterossexuais, com acesso ao capital econômico - apoderase das posições privilegiadas de riqueza e de poder no corpus social, e como é capaz de reproduzir, legitimamente, as relações sociais que geram e asseguram seu domínio (BOURDIEU, 2010). Ainda sob o olhar desse autor, a hegemonia masculina é imposta por meio de uma violência simbólica, suave, insensível e invisível a suas próprias vítimas, uma vez que, enquanto poder, ela também gera prazer e se perpetua por vias puramente simbólicas da comunicação e do conhecimento ou, mais precisamente "do desconhecimento, do reconhecimento, em última instância, do sentimento" nas sociedades, cujo eixo central é o poder androcêntrico (BOURDIEU, 2010, p. 8). 
A lógica da dominação masculina manifesta-se e perpassa todas as relações sociais, visto que é exercida em nome de um princípio simbólico conhecido e reconhecido tanto pelo dominador quanto pelo dominado (PULLEN; THANEM; TYLER; WALLENBERG, 2016). O exercício desse poder é dado por meio: a) da língua e da linguagem (a maneira de falar, expressões que podem ser utilizadas, uso de gênero); b) da cristalização da maneira de pensar (o homem deve ser mais objetivo que a mulher); c) do culto à forma de falar (o homem deve ser mais silencioso); d) da imposição de estilos de vida específicos (determinação do vestuário, de cores masculinas e femininas) e, principalmente, e) pelo controle do corpo (os machos devem ser mais contidos, gesticularem menos), conforme proposto por Bourdieu (2010).

No Weltanschauung masculino, a pior humilhação que um homem pode sofrer é ser transformado em mulher, ser feminilizado, ter sua virilidade questionada ou ser obrigado a se comportar como se fossem mulheres, uma vez que ser mulher significa "estar incessantemente consciente de seu corpo, de estar sempre exposto à humilhação ou ao ridículo e de encontrar reconforto apenas nas tarefas domésticas ou na conversa fiada com uma amiga" (NG; RUMENS, 2017).

Esses conceitos e práticas heteronormativas, que desvelam também misoginia (IRIGARAY, 2009), contribuem para o enfraquecimento do ego dos grupos minorizados e, no limite, ao necessário entrelaçamento de disposições subjetivas com fatores situacionais; ou seja, funcionam como o fermento psicológico do fascismo, nas sociedades capitalistas tardias (COLOMER, 2021).

Os mecanismos que influenciam a expansão do caráter potencialmente fascistas demandam que resgatemos os traços de personalidade e comportamentos, que fortaleçam suas raízes e, paralelamente, são fomentadas por alguns processos sociais. De fato, esse modelo de um homem agressivo, dominante e violento, sistematicamente naturalizado em romances, filmes, novelas e canções por meio dos (super) heróis.

Essa imagem idealizada, e socialmente construída, do que é ser "homem” tem permeado o debate teórico no feminismo, bem como a (cor)relação entre dominação burguesa e dominação masculina (MIGUEL, 2017).

Entretanto, nos últimos anos, mesmo que ainda de forma marginal, temos observado a emergência dos feminismos negros, indígenas, transgêneros, bem como a incorporação de classe social, como uma categoria, no bojo da discussão sobre o Capitalismo (MONTEIRO; CARVALHO, 2017). Esse tipo de sistema garante ao conjunto de homens dominantes serem 
melhores e superiores do que o resto da humanidade e, consequentemente, gera três frutos: a heteronormatividade, o machismo e a homofobia (IRIGARAY; FREITAS, 2013).

A heteronormatividade refere-se à crença na superioridade da orientação heterossexual e na consequente exclusão, proposital ou não, de indivíduos não-heterossexuais de políticas públicas e organizacionais, eventos ou atividades. A rigor, ela é a intersecção de componentes de uma ampla ideologia sobre gênero e sexualidade (PARKER, 2016). Já o machismo é oriundo do paradigma de que as mulheres existem apenas como potenciais objetos sexuais a serem disputados pelos machos e procriarem outros machos (RUMENS; SOUZA; BREWIS, 2019); portanto, são instrumentos de validação sexual da heterossexualidade e da virilidade.

A homofobia, por sua vez, resulta de três fatores: a) a homossexualidade, ao ser vista como antônimo da heterossexualidade faz com que comportamentos homofóbicos sejam vistos como um instrumento eficaz de revalidação social e (re)afirmação da heterossexualidade; b) a homossexualidade remete ao afeminamento, ou seja, iguala os gays a outra "subclasse": as mulheres e, finalmente, c) o prazer homossexual é considerado subversivo (PANIZA, 2020).

Ao se equipararem às mulheres, os homossexuais masculinos, na visão da hegemonia masculina, perdem capital social, pois são vistos como fracos e incapazes de competir (GOMES; FELIX, 2019). Por outro lado, esses indivíduos adotam estratégias de sobrevivência (IRIGARAY; FREITAS, 2013), como por exemplo, a resistência pautada na resiliência performativa; isto é, eles adotam comportamentos que os tornam aceitos perante as normas sociais vigentes, apesar dos custos psicológicos envolvidos (IRIGARAY; GOLDSCHMIDT; QUEIROZ, 2017).

Tais custos se traduzem nos esforços que precisam realizar para superar situações de estresse recorrentes nas vidas destes indivíduos, advindas de possível discriminação ou preconceito - real, iminente ou meramente percebido (IRIGARAY; GOLDSCHMIDT; QUEIROZ, 2017). Estes autores sugerem a existência de indícios que esses sujeitos se mantêm ajustados socialmente, bem como sejam superficialmente adaptados, mas que, em contraponto, ainda vivam em angústia ou omissão.

\section{PERCURSO METODOLÓGICO}

Esta pesquisa é uma continuação de outra sobre equidade de gênero nas escolas de Administração. Para este estudo, foram entrevistados 73 alunos, com idades entre 19 e 27 anos, 
dos cursos de graduação de quatro universidades, localizadas na cidade do Rio de Janeiro: uma pública (IES 1) e três privadas, sendo que duas são voltadas para o público com alto poder aquisitivo (IES 2 e IES 3) e outra para alunos com poder aquisitivo mais baixo (IES 4).

Nossos entrevistados foram de diferentes gêneros, cores de pele, classes sociais, religiões e orientações sexuais. Assim, trabalhamos com histórias de vida, compostas por fragmentos desconexos (ante narrativas e narrativas caóticas), os quais, muitas vezes, são incoerentes e ambíguos, mas que contribuem para a compreensão do todo (BOJE, 2005). De fato, por meio das histórias de vida foi possível acessar as estruturas sociais das IES e seu funcionamento, pois as narrativas das dificuldades mais pessoais, das tensões e contradições nas aparências mais subjetivas exprimem as estruturas mais profundas do mundo social e suas contradições.

No sentido de apreender a percepção dos discentes, optou-se pela etnografia, método que se coloca em um paradigma interpretacionista da realidade social. No presente estudo, dois pesquisadores são alunos de umas das IES estudadas: uma é uma mulher homossexual e o outro, um homem transexual. Portanto, esta pesquisa no campo teve também caráter autoetnográfico (ALVESSON, 2003). Se, aos alunos pesquisadores foi exigido certo estranhamento e distanciamento da realidade na qual vivem para poder sobre ela melhor refletirem, aos demais pesquisadores, foi exigida a sensibilidade para captar os sentimentos e emoções dos entrevistados.

$\mathrm{Na}$ realização das entrevistas, optamos por um roteiro semiestruturado segmentado em 4 blocos: o primeiro foi dedicado aos traços categóricos dos entrevistados; o segundo, à identidade e inserção na sociedade dos mesmos; o terceiro focou na trajetória de vida desses indivíduos; já o quarto e último foi dedicado as suas vivências no ambiente universitário.

Os relatos de nossos interlocutores que foram gravados, assim como nossas anotações de campo, foram posteriormente transcritos e submetidos à análise crítica do discurso (ACD), no sentido de apreender o corpus de interação social dos actantes. A ACD se apresenta como um "paradigma estabelecido dentro da linguística" (WODAK, 2004, p. 228) e em suas diferentes vertentes, busca adotar uma dimensão crítica sobre a linguagem, considerando-a determinante para a transformação social e para a compreensão da forma como práticas sociais e ideológicas se perpetuam, dado que ela "é um tipo de investigação analítica discursiva que estuda principalmente o modo como o abuso de poder, a dominação e a desigualdade são 
representadas, reproduzidas e combatidas por textos orais e escritos no contexto social e político" (VAN DIJK, 2008, p. 113).

$\mathrm{Na} A C D$, o discurso é concebido por meio de um processo circular, em que práticas sociais influenciam textos e falas, modelando o modo como os mesmos são produzidos, bem como o contexto social no qual são produzidos (FAIRCLOUGH, 2008). Assim, criticar é "tornar visível a interligação das coisas" (FAIRCLOUGH, 1995, p. 36), adotando uma posição política de forma explícita e focalizando a autorreflexão (WODAK, 2004).

Para a coleta de dados, valemo-nos: a) de notas de campo tomadas durante as visitas e observações; b) anotações dos diários da pesquisadora lésbica e o aluno trans e, também, das entrevistas realizadas.

No que tange às visitas e observações, estes alunos pertencem à IES 2 e, desde que se engajaram nesta pesquisa em setembro de 2018, se dedicaram ao trabalho empírico, tomando notas, ficando atentos a conversas em sala de aula, corredores e confraternizações. Quanto às IES 1, 3 e 4, foram realizadas 12 visitas (4 em cada), com a duração média de 4 horas cada, alternando-se entre os turnos diurno e noturno, no caso da IES 3 e 4, para que houvesse a familiarização com o ambiente e sujeitos.

Em alinhamento às orientações do Comitê de Ética em Pesquisa da nossa Instituição, os 73 entrevistados foram informados do real objetivo da pesquisa, tiveram anonimato e confidencialidade de seus relatos garantidos, ademais a eles foi solicitada autorização para que se gravasse a conversa. Assim, o roteiro das entrevistas se dividiu em quatro partes: na primeira, focamos nos dados categóricos autodeclarados (gênero, idade, raça, classe social, religião, orientação sexual); a segunda foi dedicada à IES em si e ao curso de graduação (por exemplo, o quanto gostava da estrutura física e do ambiente acadêmico, bem como com a escolha pelo curso de Administração); o terceiro bloco, o mais longo, foi dedicado às interações sociais com os pares e docentes (bons e maus momentos, vivências e experiências); finalmente, no quarto e último bloco, questionamos sobre o quão diferente é o ambiente universitário do familiar e social nos quais o(a) entrevistado(a) está inserido(a).

\section{REVELAÇÕES DO CAMPO}

Do total de entrevistados, 17 pertenciam à IES 1, 22 à IES 2, 15 à IES 3 e 19 à IES 4 e tinham a idade média de 21 anos, sendo que na IES 4, a faixa etária era superior às demais. Em 
termos de gênero, foram entrevistados 36 homens e 37 mulheres, proporcionalmente distribuídos entre as instituições. Majoritariamente, os alunos se declararam heterossexuais (53), 12 se assumiram bissexuais (incluindo o aluno trans-homem) e 14, homossexuais.

Já no que tange à classe social e raça/cor de pele autodeclarada, ficou patente a existência de dois grupos homogêneos de perfis do corpo discente. O primeiro composto pela IES 1 e IES 4, no qual a quase totalidade declarou "pobre" e "preto ou negro", 32 e 25 alunos (de um total de 36), respectivamente. No segundo grupo, composto pelas IES 2 e 3, 35 alunos se declaram brancos e apenas 3, os bolsistas, "pobres" (de um total de 37).

Inicialmente, focamos nossa análise da dimensão do discurso, construída com base nas noções de poder, ideologia e hegemonia; assim, ao analisarmos a prática social, a qual nos remete à dimensão macrossocial do discurso ou à forma como a produção, a circulação e a recepção dos discursos reguladas pelo contexto sociopolítico mais amplo, o campo revelou que, nas IES estudadas, há um código de ética e que todas adotam um discurso de respeito a todo e qualquer tipo de diversidade. Estes códigos são reproduzidos quase que mimeticamente, de tão similares que são. Dessa forma, há evidências de que "a constituição discursiva da sociedade não emana de um livre jogo de ideias nas cabeças das pessoas, mas de uma prática social firmemente enraizada em estruturas sociais materiais concretas, orientando-se para elas" (FAIRCLOUGH, 2008, p. 93).

A ideologia andro-heterocêntrica e o senso comum do "politicamente correto" se fazem presentes na produção, interpretação e reprodução destes discursos, o que leva os sujeitos a, sem disso se darem conta, não refletirem sobre o quanto elas se tornam políticas e práticas (CONNEL; MESSERSCHMIDT, 2013). Esse jogo de influência e imagens entre dominantes e e dominados evidencia as relações de poder no ambiente universitário e, no limite, na sociedade brasileira.

De fato, ao confrontarmos os discursos organizacionais destas organizações com a interpretação dos mesmos pelo corpo discente, verificamos que os discursos se revelaram instrumentais e retóricos. Se a prática social busca dar conta da forma como o contexto sóciohistórico regula e, até certo ponto, determina o processo de produção, circulação e recepção dos discursos (FAIRCLOUGH, 2008), a prática discursiva explica, a rigor, como esse processo ocorre em contextos institucionais particulares; isto é, como se dá a regulação e a constituição intertextual e interdiscursiva dos discursos em situações comunicativas específicas, como a sala de aula, por exemplo. Assim, do ponto de vista da prática social, o Estado e o mercado podem 
reduzir uma aula a um instrumento de reprodução de determinada ideologia e na formação de cidadãos segundo uma lógica que reproduz relações de poder econômico, as quais são privilegiam homens, brancos e heterossexuais.

Os alunos, nomeadamente os do sexo masculino, brancos, heterossexuais e de alto poder aquisitivo, revelaram-se perigosamente irracionais, na medida em que se engajaram em atos de violência moral e física contra seus pares pertencentes a grupos minoritários. Não obstante, esta violência revelou-se institucionalizada no ambiente acadêmico por meio de micropráticas sociais, e ficou claro que o objetivo das mesmas é a preservação do capital socioeconômicopolítico, que é assegurado pela hegemonia masculina, a qual se reifica por meio da desqualificação de interesses e direitos legítimos dos alunos que não pertencem ao grupo dominante.

$\mathrm{Na}$ prática, observou-se a desqualificação das mulheres, dos alunos pertencentes às classes sociais mais baixas (bolsistas nas "escolas de elite"), bem como dos não-heterossexuais e transexuais, invariavelmente, com a anuência e cumplicidade dos docentes. Assim, ao analisarmos a prática discursiva (FAIRCLOUGH, 2008), ficou evidente que os professores se desconhecem nessa arena sócio-histórica; mas, dela inevitavelmente participam, (re)produzindo um discurso (a aula), que colabora para a reprodução dessas relações de poder e corrobora com as mesmas, tanto pela escolha do conteúdo ministrado quanto pela relação que estabelece com os alunos.

Do ponto de vista do conteúdo, os professores, exceto da IES 1, tendem a se limitar pelo pragmatismo e pela aplicabilidade dos conhecimentos, bem como ao treino de tarefas úteis à inserção do aluno no mercado de trabalho. Do ponto de vista da relação estabelecida com os alunos, eles tendem a optar por aulas mais expositivas (exceto na IES 2), que reproduzem a relação de poder entre alguém que manda e alguém que obedece, entre alguém que detém um conhecimento e alguém que não detém esse conhecimento, entre alguém que fala e alguém que ouve (o que vale até para a metodologia usada na IES 2). Mais do que reproduzir as relações semelhantes às existentes no mercado (patrão e empregado), fica implícito um treinamento à subordinação e supressão de vozes e realidades alternativas.

No limite, o que deveria ser um ambiente de construção do saber, que abarcasse as múltiplas visões, torna-se um lugar de desnaturalização da práxis democrática e de instauração de fatos de situações (in)tensas, como fica evidente na análise da prática textual (FAIRCLOUGH, 2008). Nessa dimensão linguística e de construção textual do 
discurso, não busca-se proceder a uma descrição do sistema linguístico abstrato ou das propriedades lexicais, sintáticas e textuais de uma produção discursiva, mas sim dissecar em que medida a seleção lexical, as construções sintáticas, o emprego de mecanismos coesivos, a distribuição dos turnos de fala e a mobilização de determinados argumentos contribuem para a reprodução ou a subversão de discursos hegemônicos, para a naturalização de determinadas ideologias ou para a manutenção e para o reforço das relações de poder.

Essas conclusões derivaram das nossas observações e das falas dos nossos entrevistados, as quais são apresentadas agrupadas em função dos diferentes grupos identitários: classe social, gênero, cor da pele, orientação sexual e religião.

\section{CLASSE SOCIAL: DIGA-ME ONDE MORAS E EU TE DIREI QUEM TU ÉS}

Na IES 4, não foi observado nem relatado algum episódio de discriminação em função da classe social ou local de residência. Quando perguntados diretamente, a resposta sempre foi a mesma: "aqui só tem gente ferrada, que rala muito para pagar (...) sabemos que o estudo é a única forma de subir na vida". A seleção lexical "aqui só tem gente ferrada" denota um elemento de construção de identidade e senso de solidariedade social. Nessa IES, existe discriminação, mas ela se dá por outros fatores, principalmente, pela religião, nomeadamente as de matrizes africanas e afro-brasileiras.

Já os alunos da universidade pública denunciaram que, nos jogos universitários, são discriminados socialmente por todos os alunos das IES privadas, mesmo aquelas que não são voltadas para o segmento premium. Um dos entrevistados explicou que, nesses eventos e mesmo em encontros sociais, que ocorrem dentro e fora do ambiente de estudo, fica sugerido que apenas pobres estudam Administração nas universidades públicas, e que esses alunos teriam inveja de seus pares das IES particulares; o que fica desvelado no seguinte coro proferido durantes os jogos: "Ei Federal, eu tenho o pai que você quer ter", numa alusão ao eventual poder aquisitivo dos responsáveis. Por sua vez, os alunos das universidades públicas revidam, cantando que "Somos Federal, somos os filhos que seus pais queriam ter, animal", numa referência que apenas os incapazes de ingressar numa instituição pública, optariam por cursar Administração numa IES particular. As práticas discursivas (FAIRCLOUGH, 2008), nesses fragmentos de discurso, denotam, não apenas, o não reconhecimento do outro 
(SAINSAULIEU, 1977); mas também, a reificação da luta de classes e disputa por espaço político no ambiente universitário (VanDIJK, 2005).

Neste sentido, em outros depoimentos, foi sinalizado que essas tensões sociais são pautadas por fortes embates político-partidários, entre apoiadores e opositores ao atual Governo Federal. Por exemplo, na IES 2, durante uma aula, um aluno pertencente à classe dominante usou o termo "comunidade"; logo a seguir, se corrigiu, dizendo: "o Bolsonaro foi eleito e não tenho mais a obrigação de seguir esta palhaçada de politicamente correto; comunidade porra nenhuma, é favela mesmo". A seleção lexical "obrigação" revela que o indivíduo em questão entende não ter mais o dever moral de respeitar os diferentes; já que tudo que é considerado "politicamente correto" seria uma falácia ou um simples discurso de propaganda política, no caso, das administrações que antecederam a atual.

De fato, principalmente nas IES 2 e 3, observamos que o discurso oficial do governo Bolsonaro e sua família legitimou o cerceamento aos espaços sociais e políticos dos grupos minoritários em questão, principalmente, os LGBTQIA + (Lésbicas, Gays, Bi, Trans, Queer/Questionando, Intersexo, Assexuais/Arromânticas/Agênero, e mais), e os que se engajam em movimentos de resistência, como o Coletivo Mulheres.

Nas outras três IES, os alunos pertencentes às classes sociais mais baixas são vítimas de piadas e de comentários violentos. Os que mais denunciaram esses atos de discriminação foram os bolsistas das IES 2 e 3 . Um dos depoimentos mais marcantes, ao longo do nosso trabalho de campo, foi sobre uma aluna da IES 2, cujo aparelho celular não era do topo de linha e foi chamada de GBR (Garota de Baixa Renda) por um colega de sala (branco, heterossexual e rico). Neste momento, fomos informados que o uso desse acrônimo é comum entre os alunos e que as GBRs são descritas e percebidas apenas como objetos sexuais. Neste caso, ficou evidente também o discurso misógino, o que caracterizou uma discriminação de segundo grau, a qual se manifestou em outras ocasiões.

Uma das estratégias de sobrevivência desse grupo minoritário é angariar a simpatia do grupo dominante, buscando um fator identitário em comum. Duas alunas bolsistas da IES 2 relataram que um aluno bolsista frequentemente se engaja em piadas e comentários machistas e homofóbicos, o que desvela a inexistência de solidariedade entre os grupos discriminados.

Já na IES 3, as diferenças socioeconômicas não se limitam à dimensão abstrata; elas se reificam na divisão do espaço físico das salas de aula, conforme evidenciado no fragmento da fala de um aluno cotista: "é como se tivesse um muro invisível; de um lado, sentam os cotistas; 
tem o grupo do povo classe média e o menor, totalmente fechado dos filhinhos de papai, os multimilionários". Esse aluno chegou a fazer uma correlação com a favela da Rocinha, onde ele mora; pois ao lado da mesma há muros que a separam de mansões. Todavia, no espaço social universitário, há um certo grau de interação; ou em suas palavras: "a gente se fala, mas não se mistura (...) são mundos diferentes".

A rigor, os alunos cotistas tanto da IES 2 quanto da 3 se sentem como "um peixe fora d'água", pois como uma aluna explicou "rico tem cheiro de rico, tem roupa de rico" e, "tem os babacas que nos destratam; mas há outros que, apesar de legais, parecem que só sentem pena". Essa sensação de concessão e de não igualdade também se fez presente nos discursos de outros grupos minoritários com relação ao gênero e à sexualidade.

No fragmento de discurso mencionado, fica evidente que o processo de interação social, no ambiente universitário, pauta-se nomeadamente pelo efeito de posição; ou seja, a posição que o ator social ocupa em um contexto de ação específico e que condiciona seu acesso às informações pertinentes (BOUDON, 1991). Ademais, o poder de liberdade e escolha humana é limitado pela estrutura das instituições, como sugerido pela seleção lexical "peixe fora d'água"; e pela condição sócio-econômica do sujeito (WEBER, 1982), sugerida pela reificação do poder aquisitivo dos actantes (rico tem cheiro de rico").

Assim, a estratégia de sobrevivência destes grupos minoritários (IRIGARAY; FREITAS, 2013) é cerceada pelo sistema de valores, que antecede todos os outros sistemas sociais; isto é, a interiorização de normas e decisões tomadas pelos autores sociais são reguladas pela preexistência de valores incorporados pelo indivíduo, bem como por suas vivências, processos de socialização e construção de sua racionalidade (SAINSAULIEU, 1983).

\section{GÊNERO: MULHERES DO SÉCULO XXI ENFRENTANDO BATALHAS DO SÉCULO XIX}

"Sempre que estou falando sou interrompida", "10 em Matemática Financeira? Nada mal para uma garota"; "eu falo, ninguém me ouve; quando um homem fala a mesma coisa, todos concordam". Esses fragmentos resumem os depoimentos das alunas das quatro IES. Em nenhum momento se vitimizaram; entretanto, não se furtaram a denunciar os discursos e comportamentos misóginos, bem como ofensas sexuais que enfrentam no ambiente escolar e que, não raramente, extrapolam-se para redes sociais. 
Outra forma de discriminação sexista, notada na IES 2, foi a aparência física das meninas. Além do código de vestimenta, uma das entrevistadas relatou que ela se tornou um alvo quando passou a usar cabelos curtos, o que seria contra o estereótipo de beleza feminina e que "seria coisa de sapatão", segundo seus pares masculinos. O discurso machista remete-nos ao argumento que, ao tentar controlar o corpo de uma mulher, o objetivo final da sociedade patriarcal é controlar as próprias mulheres, de forma a restringir sua posição na sociedade e reduzi-las a um mero objeto de satisfação sexual para os homens (IRIGARAY; GALATOLLI; AMORIM, 2017).

Apesar de as alunas de todas as IES pesquisadas reconhecerem a discriminação em função de gênero; apenas na universidade pública identificamos a existência de um núcleo de movimento feminista organizado: o grupo Coletivo de Mulheres (GCM). Na visão das entrevistadas que participam desta organização "o movimento feminista significa liberdade em muitos aspectos, que me faz entender quem sou, quem posso ser, o que posso alcançar e o que me restringe". Essa fala desvela a importância dos grupos organizados na construção da identidade dos participantes e, no caso do movimento feminista universitário, a seleção lexical "igualdade" foi a mais citada; ou seja, a principal função deles é promover a liberdade (seleção lexical explicitamente utilizada pelas interlocutoras) da mulher numa sociedade reconhecidamente patriarcal.

O GCM promove debates sobre o papel social das mulheres, bem como suas perspectivas de vida e carreira e, sistematicamente, é confrontado por alunos heterossexuais do sexo masculino, que o trata como objeto de piada e de mulher que "não tem homem, nem um bom tanque de roupa suja para lavar". Esses indivíduos, de maneira equivocada, associam o GCM aos partidos de esquerda, contribuindo para o acirramento das animosidades dado a sociedade brasileira estar intensamente polarizada em termos de posicionamento político.

Apesar desse comportamento misógino não ser o mais comum, ele é pauta de discussão dentro do GCM; isto é, uma efetiva participação dos homens dentro dos movimentos feministas. Alguns alunos defenderam que eles podem ser atores importantes no combate à discriminação e assédio contra as mulheres; por outro lado, grande parte das participantes do GCM argumentam que eles não podem - e nem devem - participar, uma vez que o feminismo existe como uma reação à opressão que as mulheres sofrem numa sociedade patriarcal.

Nos relatos das alunas, em especial das IES 2 e 3, os atos mais violentos de assédio sexual, incluindo tentativas de estupro, ocorrem nas festas, choppadas, trotes e reuniões sociais, 
como os Jogos Universitários, o que as deixa, muitas vezes, desconfortáveis em se engajarem nas atividades sociais.

Efetivamente, os principais relatos foram a respeito dos cantos de torcida, que em sua maioria tem conotação sexual e os comentários que o papel das meninas se limita a serem líderes de torcida, e "porem a sainha curtinha e rebolarem para animar os jogadores". Esse fragmento de discurso denuncia uma postura misógina, a qual pressupõem que o papel das mulheres, na sociedade, se limite ao de objeto de prazer sexual dos homens.

A rigor, essas músicas de torcida costumam ser ofensivas a outro grupo minoritário: os LGBTQIA+, principalmente aos homossexuais masculinos, que são equiparados a "fềmeas", o que sugere a raiz dos discursos homofóbicos é a misoginia.

O futebol também exerce um importante papel na construção da identidade masculina, bem como no processo de identificação entre os homens heterossexuais. Por meio dessa atividade, os homens reiteram sua masculinidade, a qual foi, historicamente, construída com base nos traços psicográficos de "coragem", "autonomia", "habilidade", "aventura" e “solidariedade grupal” (IRIGARAY; FREITAS, 2013). De fato, o futebol é um instrumento de formação/ ratificação e cristalização da heterossexualidade masculina. Os jogadores se retratam como super-homens e as mulheres são reduzidas a meros objetos sexuais e os homossexuais reduzidos a seres abjetos (CARRIGAN; CORNELL; LEE, 2002).

Efetivamente, a masculinidade é hegemônica à medida que o poder é definido em termos de força física e controle (SWEARER; HYMEL, 2015), e o corpo masculino passa a representar a força e o poder; o qual, por sua vez, torna-se historicamente associado à força física, velocidade, controle, dureza e dominação (BOURDIEU, 2010).

Este jogo simbólico de poder e espaços sociais não passou desapercebido pelas mulheres; tanto que nas IES 2 e 3 elas se organizaram politicamente e, recentemente, assumiram o controle tanto do Diretório Acadêmico como da Empresa Junior. O desdobramento destes movimentos políticos são pauta de uma pesquisa em andamento.

\section{ORIENTAÇÃO SEXUAL: SER LGBTQIA+ E O PESO DO TRIÂNGULO COR DE ROSA}

Enquanto os soldados alemães ampliavam os domínios da Alemanha nazista pela Europa, o desejo e a prática homossexual eram varridos do território ariano com a mesma 
truculência eficiente que condenaria os judeus europeus, os doentes mentais e os ciganos.

Atualmente, apesar dos crescentes discursos de ódio, nomeadamente no mundo ocidental, é inconcebível que, em nome da pureza racial, defenda-se o extermínio de qualquer grupo minoritário. Entretanto, depois da Segunda Guerra, os sobreviventes do triângulo rosa foram os únicos a não terem benefícios das reparações que foram dadas aos outros deportados. Passaram-se décadas para que os indivíduos que não se identificassem com sexo biológico (identidade de gênero), e tivessem comportamentos afetivo-sexuais diferentes do heterossexual, não fossem considerados doentes, pervertidos ou criminosos (IRIGARAY; FREITAS, 2013)

Não obstante, esses valores heteronormativos estão encrustados na nossa sociedade (PANIZA, 2020) e pautaram os depoimentos dos nossos alunos LGBTQIA+, que se definiram "violentados por micropráticas sociais". As seleções lexicais, relacionadas às suas emoções e sensações, mais citadas foram: "angústia", "desprezo", "mágoa" e "rejeição". Mesmo os que são totalmente assumidos se sentem diminuídos como seres humanos, injustiçados, e como se não pertencessem às IES, o que gera dificuldade de interagir com seus pares, o que compromete a desejada sinergia, bem como um ambiente saudável de aprendizagem.

Nas quatro instituições, houve relatos de comportamento e atitudes heterossexistas, as quais não são penalizadas pelas IES - por meio de suas coordenações, funcionários e professores, que, também, se silenciam perante os discursos homofóbicos.

De fato, alguns alunos homens e mulheres heterossexuais se valem dessa inação e de brechas institucionais para proferirem discursos machistas e homofóbicos e, no limite, tornamse perigosamente irracionais, na medida em que se observou em alguns casos a ocorrência de atos de violência física e moral contra as minorias.

Esse foi o caso do um aluno transexual assumido, que foi agredido fisicamente, na universidade pública que cursava e, esperando encontrar um ambiente menos hostil numa IES privada, voltada para a elite carioca, também foi rejeitado na IES 3. Agora, numa última tentativa, retomou o curso na IES 2. A vida não se tornou um paraíso, pois suas falas ainda são interrompidas e ele ainda é alvo de comentários pernósticos por parte de seus colegas.

As entrevistas com as mulheres lésbicas sinalizaram que elas se sentem impactadas da mesma forma que os homossexuais masculinos; pois, a rigor, todos os comentários, piadas e brincadeiras, buscam comparar - e equiparar - os gays às mulheres; isto é, atrás do heterocentrismo jaz a homofobia, a qual, por sua vez, revela misoginia. Efetivamente, a 
desvalorização das mulheres e dos gays está imbricada na construção social das masculinidades e do conceito de gênero desde a infância, como já sinalizado por Irigaray e Freitas (2013).

As diferenças entre homens e mulheres são forjadas e enfatizadas a partir das expectativas que se estabelecem nas diversas culturas, as quais podem se alterar ao longo do tempo. Contudo, a concepção de uma natureza fundante, capaz de explicar os comportamentos masculinos e femininos, ainda persiste e se revela nos estereótipos (GOMES; FELIX, 2019). Dessa forma, assumir-se homossexual no ambiente universitário significa ter seu espaço social limitado, ou seja, perda de capital político-econômico.

Assim como ocorre com as mulheres, as atividades esportivas, nomeadamente o futebol, é fonte de segregação, pois os homossexuais masculinos tendem a não ser convidados e, até mesmo, espontaneamente, evitar participar das "peladas", como desvelado no fragmento de discurso de um aluno da IES 3: "É lógico que me sinto excluído, essas peladas são muito mais do que um jogo de futebol, é quando eles formam a fraternidade, o famoso networking”. Esse fragmento de discurso reforça a ideia de que essas práticas esportivas são percebidas como um meio de segregação, que lhes causam sofrimento por dois motivos: a) a exclusão em si, que lhe fere a autoestima, como ele relatou em outra situação, e b) o sequestro do seu senso de pertencimento ao corpo discente, que ficam patentes nas seleções lexicais "excluído" e "fraternidade", respectivamente.

A hegemonia masculina é reificada na prática textual (FAIRCLOUGH, 2008), especificamente, nas construções sintáticas e emprego de mecanismos coesivos do grupo dominante, bem como pela distribuição dos turnos de fala. Mais uma vez, como já sinalizado por Irigaray e Freitas (2013) tanto as falas das mulheres quanto os homo e bissexuais masculinos e, até mesmo dos homens trans, são ignorados; todavia, eles se mobilizam e estruturam argumentos que subvertem os discursos hegemônicos, no sentido de desnaturalizar a ideologia dominante (CONNEL; MESSERSCHMIDT, 2013) e confrontarem e desafiarem as relações de poder (BOURDIEU, 2010; MIGUEL, 2017).

\section{COR DA PELE: CADÊ MEUS PARES?}

As IES 1 e 4, em função de suas características, respectivamente, pública e privada voltada para um público de baixo poder aquisitivo apresentam um ambiente acadêmico mais diverso, no que tange seus corpos discentes. Por isso, os episódios e relatos de atos e discursos 
racistas foram raros; os poucos que ocorreram se remeteram a piadas e brincadeiras de mau gosto.

Por outro lado, as IES 2 e 3 são votadas para a elite, suas mensalidades são altas e ambas são localizadas na zona sul do Rio de Janeiro. São poucos os alunos não-brancos, dos quais, a maioria é cotista, o que sinalizou uma intersecção entre a discriminação em função da cor da pele e da classe social.

Os poucos alunos não-brancos bolsistas encontram dificuldade em formarem grupos de estudo e se socializarem. O fragmento de discurso mais ouvido foi: "eu sinto que não pertenço aqui. Aqui não é meu lugar". Esse não pertencimento é um reflexo da abordagem assimilacionista, que prevalece no contexto racial brasileiro (CANDAU, 2011), cuja principal característica é a (falsa) crença que os processos de miscigenação integrariam as culturas e fariam desaparecer as especificidades de cada grupo étnico, evitando os conflitos culturais. Esse é o argumento que sustenta o mito da democracia racial brasileira, defendido pelas elites dos anos 1930.

Essa falsa sensação de uma democracia racial é desmascarada pela segregação simbólica e pelo silenciamento dos alunos, que afirmam "não ter o que falar" ou "como participar das aulas".

Todavia, também entrevistamos alunos negros estrangeiros, que participam de um programa de intercâmbio dos cursos de graduação. Estes 9 alunos e alunas, oriundos da França, Alemanha, Estados Unidos e Holanda afirmam ser muito bem tratados pelos seus colegas brasileiros, que são muito hospitaleiros e demonstram interesse nos programas e cursos das universidades europeias e estadounidenses.

Essa postura dos alunos brasileiros, tão hostis aos seus compatriotas não-brancos, reforçam a ideia de que suas atitudes são sustentadas pelas disparidades sociais, e que a elite nacional ainda mantém uma mentalidade colonial, como já sinalizado por Holanda, Araújo e Schwatz (2006).

\section{PARA CONCLUIR}

$\mathrm{Na}$ ótica androcêntrica, pertencer ao sexo masculino e ser heterossexual é a garantia de capital social e facilidade de acesso ao capital econômico. Ao contrário das mulheres, as quais são discriminadas e estigmatizadas em função de suas características físicas, os gays o são pela 
percepção social de que sua orientação afetiva é um desvio de conduta moral, o qual comprometeria seus desempenhos acadêmicos e profissionais.

Assim, nas universidades, os homossexuais masculinos são associados à fragilidade, medo e inconsequência, o que desvela a heteronormatividade como um dos pilares de nossa sociedade. Essa crença na superioridade da orientação heterossexual implica na invisibilização e, no limite, na exclusão, proposital ou não, de indivíduos não-heterossexuais de espaços sociais, de políticas públicas e organizacionais. Por não ser explícita e socialmente aceita, a heteronormatividade estigmatiza, nega e menospreza manifestações não-heterossexuais.

No trabalho de campo, também ficou patente que o fato de indivíduos pertencerem a diferentes grupos minoritários não os iguala nem promove um senso de solidariedade. Assim, homens e mulheres pobres e não-brancos não se furtam em usar artifícios e argumentos heterossexistas para discriminar seus colegas LGBTQIA+, visando a angariar a simpatia do grupo dominante (homens, brancos, heterossexuais).

O comportamento heterossexista revelou-se incrustado no corpus das quatro instituições e ficou claro que seu objetivo é a preservação do capital sócio-econômico-político garantido pela hegemonia masculina, a qual se reifica por meio da desqualificação de interesses e direitos legítimos seus pares que pertencem aos grupos minoritários. A rigor, essa desqualificação é lograda por meio da desnaturalização eficaz da práxis democrática e da instauração de fatos e situações intensas de força que perpetuam o status quo.

As implicações do presente estudo se colocam para a academia, para as IES e para a sociedade como um todo. No que diz respeito à academia, é papel dos pesquisadores buscarem compreender melhor a realidade do ambiente no qual atuamos e resgatarmos as realidades e vozes de alunos que são negligenciadas e silenciadas quando elaboramos nossos programas, planos de aula e ministramos nossas aulas.

Acreditamos também que as IES devem se engajar, efetivamente, no combate a qualquer tipo de discriminação, no sentido de garantirmos um melhor ambiente de aprendizagem para nossos alunos. Em relação à sociedade, espera-se que seja responsável pelo reconhecimento da cidadania dessas minorias.

Enveredar por essas implicações parece ser uma adequada sugestão para futuras pesquisas, como por exemplo: a) estudar a influência dos discursos e das práticas políticas, vigentes no país, nas interações sociais nos ambientes acadêmicos; b) a possibilidade em descolonizarmos as escolas de negócios, nomeadamente os currículos dos cursos de 
Administração e materiais de estudo; c) repensamos as teorias e as práticas do nosso campo de estudo sob os olhares queer e feministas; ou ainda, d) repensar o perfil dos egressos desejado para a construção de uma sociedade mais justa e igualitária.

\section{REFERÊNCIAS}

ALVESSON, M. Methodology for close up studies: struggling with closeness and closure. Higher Education, v. 46, n. 2, p. 167-193, 2003.

BAUDRILLARD, J. Simulacra et Simulation. Paris: Gallimard, 1968.

BENHABIB, S. Postmoderism and Critical Theory: On the Interplay of Ethics, Aesthetics and Utopia in Critical Theory. Cordozo Law School Review, v. 11, p.1435-1449, julho / agosto 1990.

BERGER, P.; LUCKMAN, T. A construção social da realidade. 26 ed., Rio de Janeiro: Vozes, 2006.

BERLINCK, M. Homo sociologicus: Ensaio sobre a história, o significado e a crítica da categoria de papel social. RAE - Revista de Administração de Empresas, v.10, n.1, p. 347$372,1970$.

BOUDON, R. L’idéologie. Paris: Seuil, 1991.

BOJE, D. Stories of the Storytelling Organization: A Postmodern Analysis of Disney as “Tamara-Land". Academy of Management Journal, v. 38, n. 4, p. 997-1035, 2005.

BOURDIEU, P. A dominação masculina. 9 ed., Rio de Janeiro: Ed. Bertand Brasil, 2010.

BROD, H. (Ed.). The Making of Masculinities: The New Man's Attitudes. Boston: Allen and Unwin, 2002.

CANDAU, V. M. Multiculturalismo e educação: Desafios para a prática pedagógica. In: CANDAU, V. M.; MOREIRA, F. A. (orgs). Multiculturalismo: diferenças culturais e práticas pedagógicas. 7 ed., Petrópolis: Vozes, 2011.

CARRIGAN, T.; CORNELL, B.; LEE, J. Toward a New Sociology of Masculinity. In: BROD, H. (Ed.). The Making of Masculinities. Boston: Allen and Unwin, 2002.

COLOMER, J. El debilitamiento del yo em el tardocapitalismo y la nueva propaganda fascista. Oxímora. Revista Internacional de Ética y Política, n.18, p. 37-55, 2021.

CONNEL, R.; MESSERSCHMIDT, J. Masculinidade hegemônica: repensando o conceito. Revista Estudos Feministas, v. 21, n. 1, p. 241-282, 2013. 
DIAS, E.; SOUZA-NETO, J. Diversidade cultural no espaço escolar: implicações no ensino, na aprendizagem e nos processos de subjetivação. EccoS - Revista Científica, n. 48, p. 5170, 2019.

FAIRCLOUGH, N. Critical discourse analysis. London: Longman , 1995.

FAIRCLOUGH, N. Discurso e mudança social. Brasília, DF: Ed. UnB, 2008.

FELIX, B. O Self que (não) fala: um modelo baseado em identidades sobre voz e silêncio de empregados. Cadernos EBAPE.BR, v. 18, n. 3, p. 557-571, 2020.

GARCIA, J. G. Orientação sexual e discriminação: um experimento no mercado de trabalho paulistano, 2017, 67f. Tese (Doutorado em Administração de Empresas), EAESP, Fundação Getulio Vargas, São Paulo, 2017.

GODINHO, C. A violência no ambiente universitário. Revista Brasileira em Promoção e Saúde, v. 31, n.34, p.-18, 2018.

GOFFMAN, E. Ritual de interação: ensaios sobre o comportamento face a face.

Petrópolis: Vozes, 2011.

GOMES, R.; FELIX, B. O self no armário: uma teoria fundamentada sobre o silêncio de gays e de lésbicas no ambiente de trabalho. Cadernos EBAPE.BR, Rio de Janeiro, v. 17, n. 2, p. 375-388, fev. 2019.

HASSARD, J. Sociology and Organization Theory: Positivism, Paradigms and Postmodernity. Cambridge: Cambridge University Press, 1993.

HOLANDA, S.; ARAÚJO, R.; SCHWARZ, L. Raízes do Brasil. Rio de Janeiro: Companhia das Letras, 2006.

IRIGARAY, H.; GALATOLI, C.: AMORIM, D. Gender Equity in Business Schools: What Has Been Promoted? Anais... EnGPR 2017, Curitiba.

IRIGARAY, H.; GOLDSCHMIDT, C.; QUEIROZ, L. Resiliência, Orientação Sexual e Ambiente de Trabalho: Uma Conversa Possível? Revista de Gestão Social e Ambiental, v. 11, n. Ed. Especial, p. 40-54, 2017.

IRIGARAY, H; FREITAS, M. Estratégia dos Gays no Ambiente de Trabalho. Revista de Psicologia Política, n.13, p. 57-74, 2013.

LUZ, M. O interacionismo simbólico: breve exposição de uma corrente acionista em ciências sociais. UERJ: Instituto de Medicina Social, 1993. 
MEURER, J. L. Gêneros textuais na análise crítica de Fairclough. In: MEURER, J. L.; BONINI, A.; MOTTA-ROTH, D. (Org.). Gêneros: teorias, métodos, debates, p. 81-107. São Paulo: Parábola, 2005.

MIGUEL, L. Voltando à discussão sobre capitalismo e patriarcado. Revista Estudos Feministas, v. 25, n. 3, p. 12-19, 2017.

MONTEIRO, M.; DE CARVALHO, G. Mulheres na Política: reflexões sobre as Lutas Identitárias X Sociedade Patriarcal Capitalista. Revista de Teorias da Democracia e Direitos Políticos, v. 2, n.2, p. 207-22, 2016.

NG, E.; RUMENS, N. Diversity and inclusion for LGBT workers: Current issues and new horizons for research. Canadian Journal of Administrative Sciences, n. 34, p. 109-120, 2017.

OLFERT, M.; BARR, M.; CHARLIER, C.; GREENE, G.; ZHOU, W.; COLBY, S. Sex differences in lifestyle behaviors among US college freshmen. International Journal of Environmental Research and Public Health, v.16, n. 3, p. 78-95, 2019.

PANIZA, M. Entre a emergência, a submersão e o silêncio: LGBT como categoria de pesquisa em Administração. Cadernos EBAPE.BR, Rio de Janeiro, v. 18, n. 1, p. 13-27, jan. 2020.

PARKER, M. Queering queer. Gender, Work and Organization, n. 23, p. 71-73, 2016.

PARSONS, T. The Structure of Social Action. New York: McGraw-Hill Book Company, 1937.

PULLEN, A.; THANEM, T.; TYLER, M.; WALLENBERG, L. Sexual politics, organizational practices: Interrogating queer theory, work and organization. Gender, Work and Organization, n.23, p. 1-6, 2016.

RUMENS, N.; SOUZA, E.; BREWIS, J. Queering Queer Theory in Management and Organization Studies: Notes Towards queering heterosexuality. Organization Studies, v. 4, n. 4, p. 593-612, 2019.

SAINSAULIEU, R. La régulation culturelle des ensembles organisées. L'année sociologique, v. 5, n. III, p. 195-217, 1983.

SARAIVA, L.; IRIGARAY, H. Políticas de Diversidade: Uma Questão de Discurso? RAE. Revista de Administração de Empresas, v. 49, p. 337-348, 2009.

SWEARER, S.; HYMEL, S. Bullying and Discrimination in Schools: Exploring Variations Across Student Subgroups. School Psychology Review, v.44, n. 4, p. 504-590, 2015.

Van DIJK, T. Discurso e poder. São Paulo: Contexto, 2008. 
WEBER, M. A Ciência como Vocação. IN: Ensaios de Sociologia. $5^{\text {a }}$ ed. Rio de Janeiro: LTC/Editora, 1982.

WODAK, R. Gender and Discourse. Londres: Sage, 1997.

WODAK, R. Do que trata a ACD: um resumo de sua história, conceitos importantes e seus desenvolvimentos. Linguagem em (Dis)curso, v. 4, n. especial, p. 223-243, 2004. 